\title{
PARAMETRIC MANDIBLE RECONSTRUCTION PLATE
}

\author{
B.I. Giddy ${ }^{1 \#} \&$ J. van der Merwe ${ }^{1 \dagger *}$
}

\section{ARTICLE INFO}

\section{Article details}

Presented at the $21^{\text {st }}$ annual international conference of the Rapid Product Development Association of South Africa (RAPDASA), held from 4-6 November 2020.

Available online

11 Nov 2020

\section{Contact details}

Corresponding author jovdmerwe@sun.ac.za

\section{Author affiliations}

1 Department of Mechanical and Mechatronic Engineering, Stellenbosch University, South Africa

\# The author was enrolled for an MEng (Mechanical) degree in the Department of Mechanical and Mechatronic Engineering, Stellenbosch University, South Africa

$\dagger \quad$ The author was enrolled for a DPhil (Mechanical Engineering) degree in the Department of Mechanical and Mechatronic Engineering, Stellenbosch University, South Africa

\section{ORCID ${ }^{\circledR}$ identifiers}

B.I. Giddy

https://orcid.org/0000-0002-9840-9095

J. van der Merwe

https://orcid.org/0000-0003-3579-654X

\section{DOI}

http://dx.doi.org/10.7166/31-3-2444

\section{ABSTRACT}

This study investigated the feasibility of a parametric mandible reconstruction plate in order to reduce surgical lead time, improve fit, and reduce residual stresses. The parametric plates were generated on the basis of simulated cephalometric measurements. A finite element analysis and a reconstruction plate/mandible fit test were performed on several combinations to determine whether the parametric plate provided a suitable alternative to conventional reconstruction plates in terms of fit and structural performance. The results indicated that the parametric plate is structurally superior to a conventional plate. The comparison test indicated that the parametric plate provides a reasonable approximation of mandible geometry.

\section{OPSOMMING}

Hierdie studie ondersoek die vatbaarheid van 'n parametriese mandibel rekonstruksieplaat om die sjirurgiese aanvoortyd te verminder, die passing te verbeter en om die resspannings te verminder. Die parametriese plate is genereer aan die hand van gesimuleerde kefalometriese afmetings. ' $n$ Eindige element analise en rekonstruksie plaat-mandibel passing toets is uitgevoer op verskeie kombinasies om te bepaal of die parametriese plaat 'n gepaste alternatief tot konvensionele rekonstruksie plate bied in terme van passing en strukturele vertoning. Die resultate toon dat die parametriese plaat struktureel beter is as 'n konvensionele plaat. Die toets het ook aangedui dat die plaat 'n redelike skatting van mandibel geometrie verskaf.

\section{INTRODUCTION}

The mandible is the largest and strongest bone in the facial skeleton. It frames the lower portion of the face, and is an integral component in breathing, speaking, chewing, and swallowing [1]. Severe trauma to the mandible can result in the resection of the damaged region, which is commonly treated using mandible reconstruction plates. These plates are straight bars of titanium, with appropriately spaced holes, that are used to anchor the plate to the skeleton by way of locking screws. During surgery, the surgeon uses bending and cutting guides to shape the implant.

Implant fit is affected by the complexity of the geometry, the implant length and, most importantly, surgical experience [2]. It is of utmost importance that the implant is correctly shaped, as a mismatch between patient geometry and plate geometry may result in plate failure, the patient having difficulty 
with the associated activities of daily living, and poor aesthetics [3]. An important phenomenon to consider when shaping implants is the residual stress induced by plastic deformation of the material. Weakening of the material and micro-tears at the bending site often result in plate failure [4].

A patient-specific mandible reconstruction plate could alleviate the problems encountered when manually shaping implants. Typically, a designer will create a three-dimensional model of the patient's mandible. This model will then be used to generate a patient-specific mandible reconstruction plate that the surgeon can implant with little or no adjustment. A customised reconstruction plate could improve mandible functionality and aesthetics, and significantly reduce the chance of mandible and/or plate fracture [5]. However, the patient-specific process is complex and time-consuming.

The parametric mandible reconstruction plate described in this work is in the middle ground between conventional and custom plates. During the design process, a parametric template is adapted to a cephalometric analysis of a three-dimensional reconstruction of the patient's mandible. The primary difference between patient-specific and parametric plates is that the latter consist of a computer-aided drawing (CAD) template, which does not need to be created from scratch for each iteration.

This research paper contributes to the following:

- A decrease in lead time for mandible reconstruction plates

- A reduction in the difficulties associated with bending

- An improved implant fit and performance, potentially reducing failure rates

\section{METHODOLOGY}

This section describes the parametric reconstruction plate design process. Initially, a CAD template of the reconstruction plate was generated using cephalometric data. Random mandible samples were generated and measured. The corresponding reconstruction plates were generated from the CAD model in step 1, and a comparison test was performed to analyse the mandible/plate fit. Finally, a finite element analysis (FEA) was performed on the male mandible which exhibited the most curvature and the corresponding plate.

\subsection{Implant design}

The parametric mandible reconstruction plate was created in Inventor (Autodesk, California, San Rafael, USA). The template was based on the average cephalometric measurements taken between the landmarks shown in Figure 1 and Table 1 [6]. These landmarks were plotted in space, and a three-dimensional sketch was used to create a closed path between these points. Figure 2 shows the three-dimensional sketch used in the construction of the template. Figure 3 is a top-down view that shows the angular measurements used to generate the holes on the body region of the plate. Angular measurements proved consistent, and allowed for simple adjustment of the hole positions. The holes on the ramus region of the plate were generated using a rectangular pattern. Table 2 shows the parameters that defined the cephalometric relationships. The plate dimensions could be controlled from this dialogue box alone. The profile of the plate was sketched, and a sweep - from the left condyle to the right condyle - was performed to generate the full parametric plate. Fillets of $0.3 \mathrm{~mm}$ were applied to soften the edges of the plate and protect any surrounding tissue. Figure 4 shows the final parametric reconstruction plate.

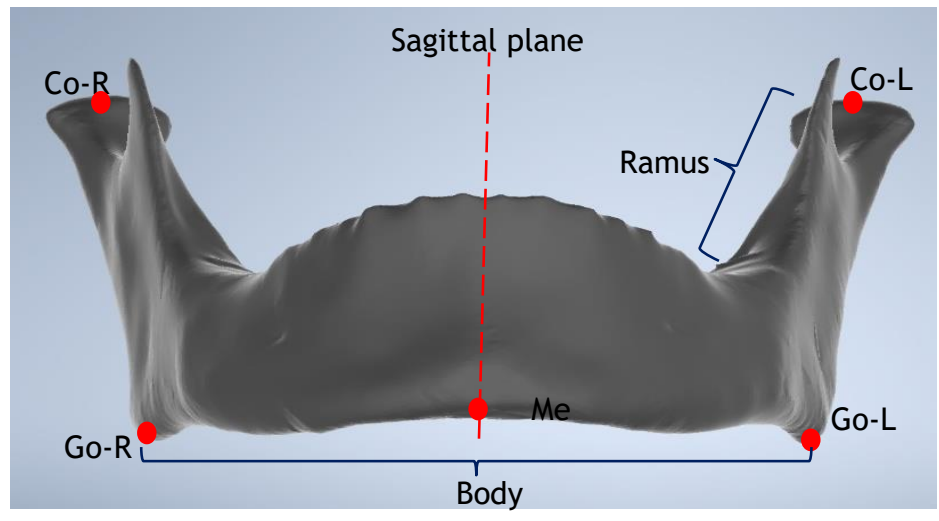

Figure 1: Parametric landmarks 


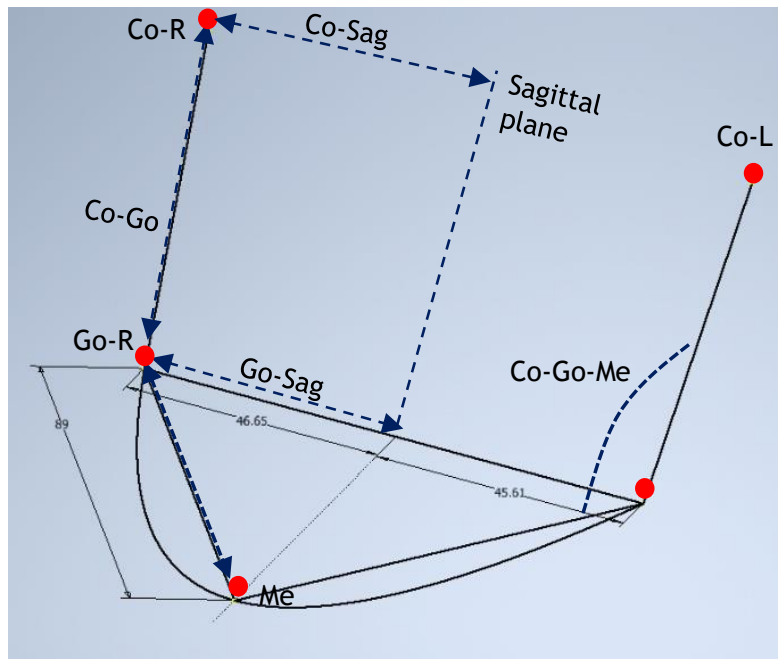

Figure 2: Three-dimensional construction sketch

Table 1: Parametric landmark descriptions

\begin{tabular}{|l|l|l|}
\hline Landmarks & Symbol & Description \\
\hline Condyle & Co & $\begin{array}{l}\text { The most posterior point found } \\
\text { on the condyle }\end{array}$ \\
\hline Gonion & Go & $\begin{array}{l}\text { The most inferior and posterior } \\
\text { point found on the angle }\end{array}$ \\
\hline Menton & Me & $\begin{array}{l}\text { The most inferior point on the } \\
\text { chin, found along the sagittal } \\
\text { plane }\end{array}$ \\
\hline Sagittal plane & $\begin{array}{l}\text { The sagittal plane is an } \\
\text { anatomical plane that divides } \\
\text { the body into right and left } \\
\text { parts }\end{array}$ \\
\hline
\end{tabular}

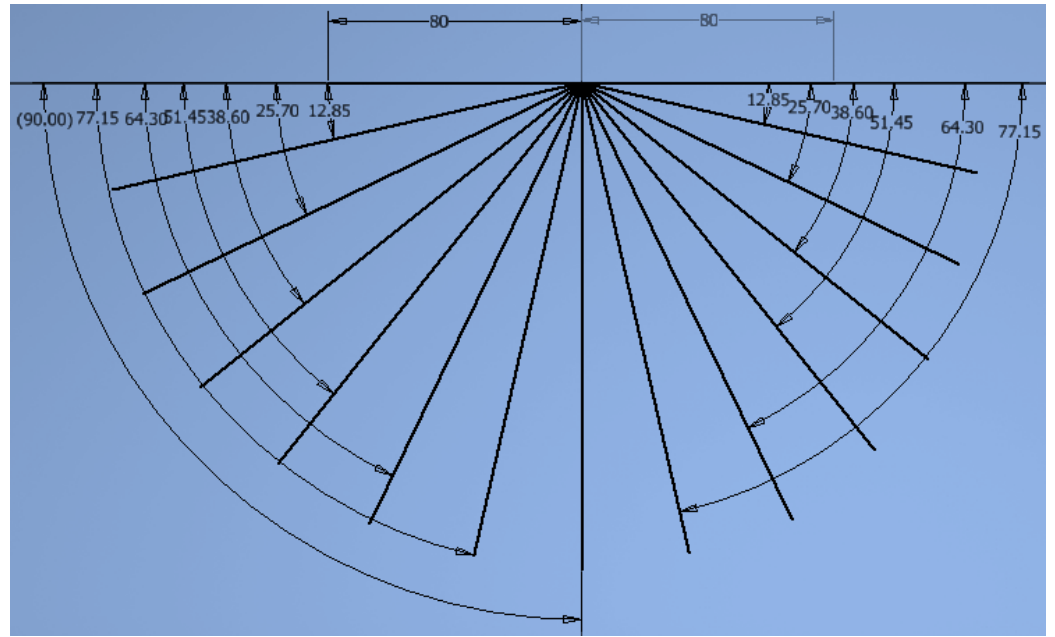

Figure 3: Angular positions of the screw-holes 


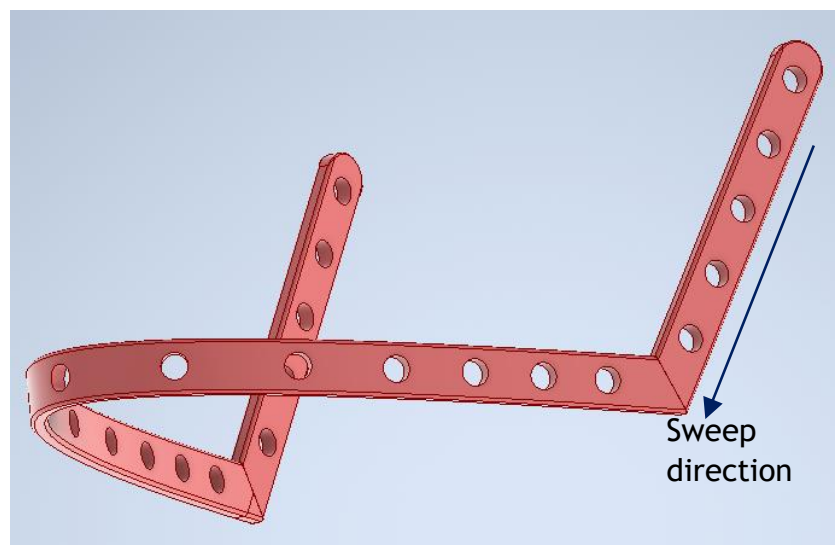

Figure 4: Parametric mandible reconstruction plate

Table 2: Parameter space

\begin{tabular}{|l|l|l|}
\hline Model parameters & Value & Unit \\
\hline Go-Sag-L & 45.61 & $\mathrm{~mm}$ \\
\hline G-Sag-R & 46.65 & $\mathrm{~mm}$ \\
\hline Go-Me & 89 & $\mathrm{~mm}$ \\
\hline Co-Go-R & 58.52 & $\mathrm{~mm}$ \\
\hline Co-Go-Me-R & 115 & $\mathrm{deg}$ \\
\hline Co-Go-L & 57.69 & $\mathrm{~mm}$ \\
\hline Co-Go-Me-L & 115 & $\mathrm{deg}$ \\
\hline Co-Sag-L & 50.04 & $\mathrm{~mm}$ \\
\hline
\end{tabular}

\subsection{Simulated mandible samples}

The randomised mandible samples were generated using a statistical shape model developed from population data that was obtained from a statistical shape model developed by Gillingham [6]. The shape model samples use a standard Gaussian distribution, or bell curve. This is a common continuous probability distribution that states that, given sufficient sample size, the averages of independently drawn samples from the same distribution converge to the normal, with 68 per cent of sample values within \pm 1 standard deviation, 95 per cent of sample values within \pm 2 standard deviations, and 99.7 per cent of values within \pm 3 standard deviations. A shape can be represented as a collection of points. If a training set of shapes the population data - is aligned according to the same frame of reference and then superimposed, a distribution of the points that make up the training shapes can be observed. Principal component analysis uses orthogonal transformations to convert correlated values in the point distribution into a set of linearly uncorrelated variables called principal components. These principle components, in conjunction with the point distribution model, make up the statistical shape model, and explain or provide a solution for how the points, and ultimately the shapes, differ within the training data.

\subsection{Comparison test}

A comparison test was performed to evaluate the fit between 16 simulated mandibles that were generated as previously described and their corresponding plates. For each mandible, the landmarks shown in Figure 1 and Table 1 were identified and their three-dimensional coordinates were stored. These coordinates were imported into MATLAB; the measurements were calculated, and then used to create 16 corresponding parametric mandible reconstruction plates from the template.

Each mandible/plate combination was imported into MeshLab in .stl format. The point-based glueing method - in which the landmarks, shown in Figure 2, are manually selected on the mandible and parametric plate - was used to align the models. In order to determine the fit, the Hausdorff distance, Equation 1, was calculated [7].

\section{Equation 1: Hausdorff distance}

$$
d_{H}(X, Y)=\max \left\{\sup _{x \in X} \inf _{y \in Y} d(x, y), \sup _{y \in Y} \inf _{x \in X} d(x, y),\right\}
$$


Here sup represents the supremum and inf the infimum. The Hausdorff distance was used because it measures the distance between two subsets of a metric space. The Hausdorff equation measures the distance from one point on the sampled mesh to the closest point on the target mesh. In this case, the plate is selected as the sampled mesh and the mandible as the target mesh. Positive values indicate a good approximation of the underlying mandible, and negative values indicate interference between the meshes. The RMS or root mean square value is used to describe the average distance between each mesh point.

\subsection{Finite element analysis}

An ANSYS Student licence was used to perform FEA. The parametric reconstruction plate was compared with a conventional reconstruction plate with simulated cold work caused by bending, to investigate the differences in the resulting stresses between the two. The mean male mandible model obtained from the statistical shape model was used to conduct the FEA study. This model consisted of over 90000 faces, but was reduced to 250 faces to comply with the ANSYS Student limitations. The mandible file was converted from the. stl format to a solid body and exported as a Parasolid file. A simulated mandibular resection of $30 \mathrm{~mm}$ was performed, as shown in Figure 5 . The simulated defect length varies across the literature; but the location, between the last molar and the second bicuspid, remains consistent [8] [9] [10].

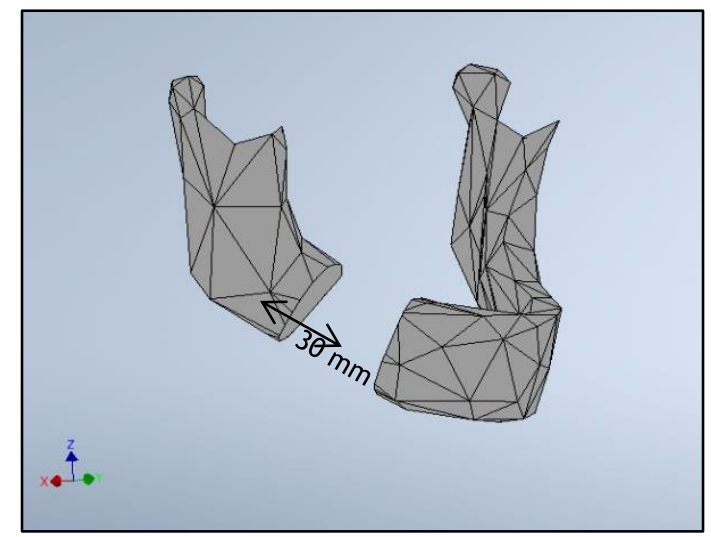

Figure 5: Reduced model with simulated defect

The corresponding parametric and conventional reconstruction plates were generated by drawing a bounding box of $52 \mathrm{~mm}$ perpendicular to the required region. An extrusion was used to generate the shorter plate, and a rounding of sharp edges and fillets was added. The number of screws and the spacing required for mandible defects is not well documented. However, some conclusions can be drawn from the literature. Smaller defects, such as fractures and short resections, have two screws on either side of the defect [11] [12] [13]. Larger defects, which can extend from the Me landmark to below the sigmoid notch, have upwards of three screws on either side of the defect [14] [15]. Two holes on either side of the resection were deemed appropriate for this analysis setup.

The mandible/plate combination was aligned and imported into ANSYS. The mandible material was assumed to be homogeneous and isotropic, with a Young's modulus of $13700 \mathrm{MPa}$ and a Poisson's ratio of 0.3 [16]. The conventional and parametric reconstruction plates were modelled as Ti-6Al-4V, with a Young's modulus equal to $107 \mathrm{GPa}$ and a Poisson's ratio of 0.323. A default mesh was generated and assigned to the models. Mesh editing was performed to improve two criteria: overall element quality and aspect ratio [17]; and a mesh independence study was performed to analyse solution convergence. The boundary conditions and values were adapted from work by Wu, Lin, Liu and Lin [18]. The muscle force values were based on a lateral incisal displacement of $5 \mathrm{~mm}$. Figure 6 shows the mandible muscles, and Table 3 shows the boundary condition values and muscular references. 


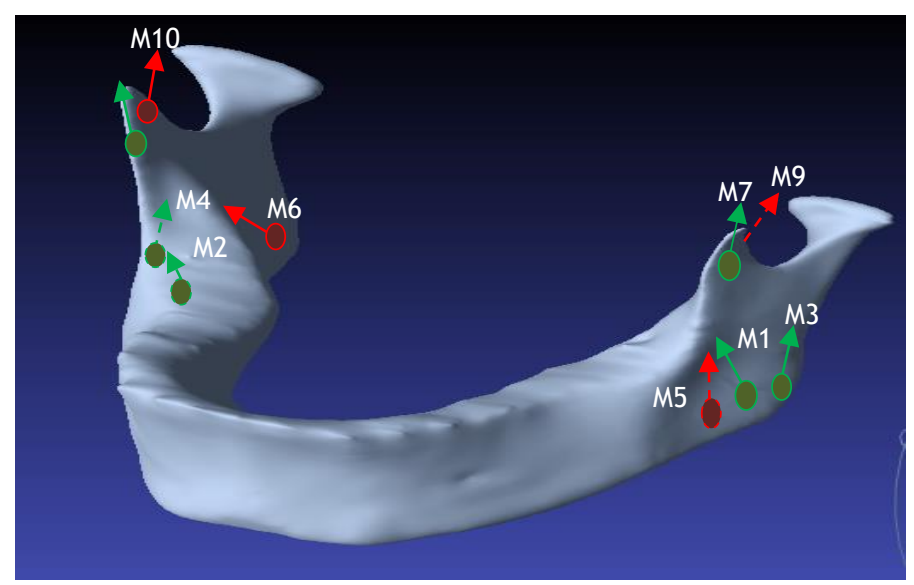

Figure 6: Mandible muscle attachment sites

Table 3: Boundary condition values (Wu, Lin, Liu and Lin, 2017)

\begin{tabular}{|c|c|c|c|c|}
\hline \multirow[t]{2}{*}{ Muscle } & \multicolumn{3}{|c|}{ Loading $(N)$} & \multirow[t]{2}{*}{ Reference } \\
\hline & $X$ & $Y$ & $Z$ & \\
\hline $\begin{array}{l}\text { Deep } \\
\text { masseter }\end{array}$ & 7.776 & 127.23 & 22.68 & $M 1,2$ \\
\hline $\begin{array}{l}\text { Superficial } \\
\text { masseter }\end{array}$ & 12.873 & 183.5 & 12.11 & $M 3,4$ \\
\hline $\begin{array}{l}\text { Medial } \\
\text { pterygoid }\end{array}$ & 140.38 & 237.8 & -77.3 & M5, 6 \\
\hline Temporalis & 0.064 & 0.37 & -0.13 & M7, 8 \\
\hline $\begin{array}{l}\text { Medial } \\
\text { temporal }\end{array}$ & 0.97 & 5.68 & -7.44 & M9, 10 \\
\hline
\end{tabular}

The FEA of the conventional plate uses the same mesh model as the parametric plate, but with added residual stress to model the plastic deformation induced by bending during surgery. This residual stress was simulated as a thermal load and applied to the conventional reconstruction plate. This approach is like that described by O'Toole, Karpanan and Feghhi [19] and Murugan, Kurian, Jayaprakash and Sreedharapanickar [20]. Thermal stress is calculated using Equation 2, where E is Young's modulus, $a$ is the thermal expansion coefficient, and $\Delta T$ is the change in temperature. The residual stress value in the plate can vary owing to factors such as bending, the initial temperature of the plate, plate length, thickness, and the number of screws. The post-operative performance of the plate, in turn, is affected by the patient's bone health, defect size, chemotherapy or radiation treatment, geometry, and age. These factors, when considered together, make it difficult to model a consistent residual stress value. Therefore a residual stress value of $105 \mathrm{MPa}$ was chosen to differentiate the parametric plate from the conventional plate. Thermal stress was applied to the plate using a thermal condition in the FEA setup.

\section{Equation 2: Thermal stress}

$$
\boldsymbol{\sigma}=\boldsymbol{E} * \alpha * \Delta T
$$

\section{RESULTS}

The mean Hausdorff values for the comparison of 16 mandibles are displayed in Table 4. An example of a typical comparison test is illustrated in Figure 7. Blue indicates that the plate is oversized, green indicates a good approximation, and red means that there is interference between the plate and the mandible.

Table 4: Mean Hausdorff values for 16 comparison tests

\begin{tabular}{|l|l|l|l|l|}
\cline { 2 - 5 } \multicolumn{1}{c|}{} & Min & Max & Mean & RMS \\
\hline Male & 0.00185 & 5.9068 & 2.000968 & 2.431303 \\
\hline
\end{tabular}




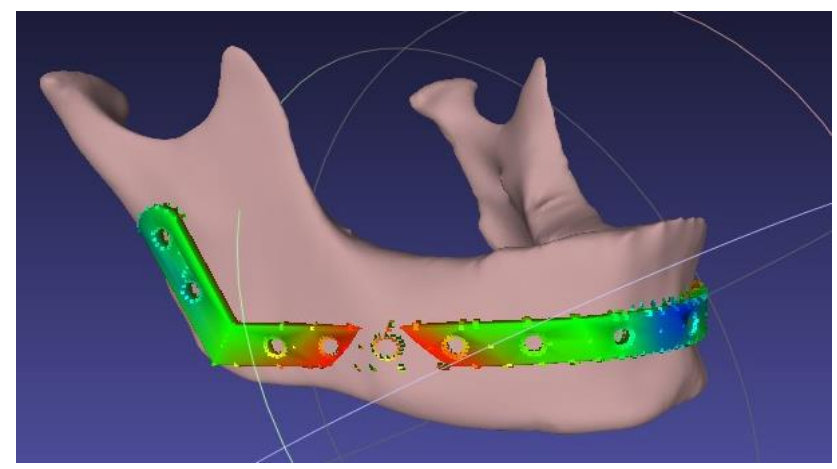

Figure 7: Mandible comparison test

Figure 8 shows the final FEA setup and the applied mesh. The muscle forces, fixed supports, thermal load, and displacement conditions were applied directly to the mandible as described in the text and as shown in Figure 6. The male conventional reconstruction plate, shown in Figure 9-a, has a maximum Von Mises stress of $224.91 \mathrm{Mpa}$, and an average stress of $\pm 77 \mathrm{MPa}$. The maximum Von Mises stress in the parametric reconstruction plate is $132.63 \mathrm{Mpa}$, with an average stress of $\pm 44 \mathrm{Mpa}$, shown in Figure 9-b.

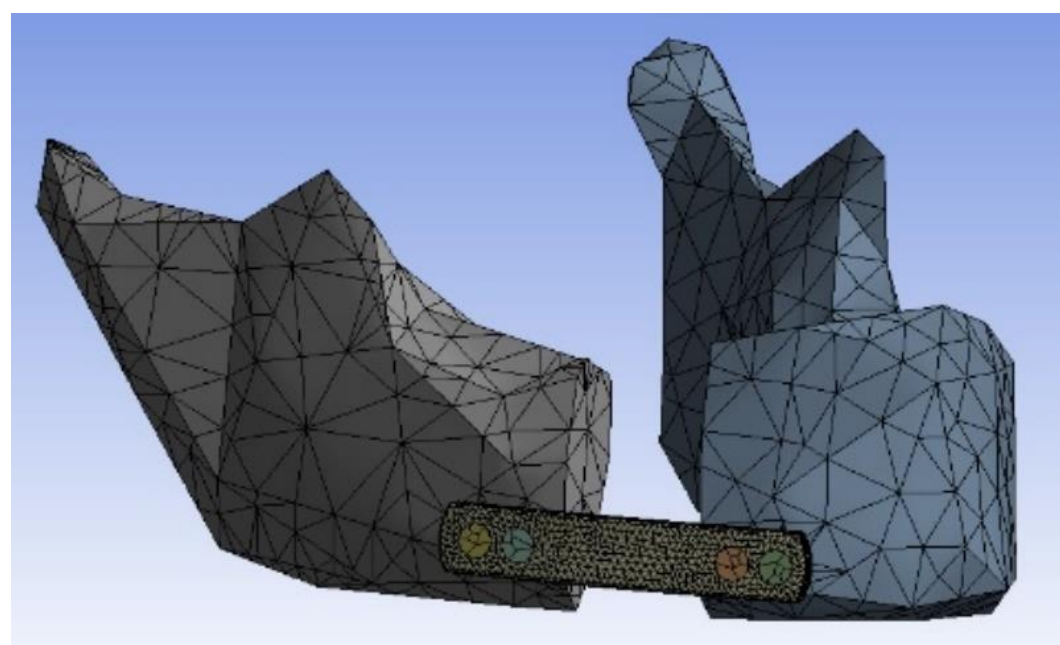

Figure 8: Final FEA setup

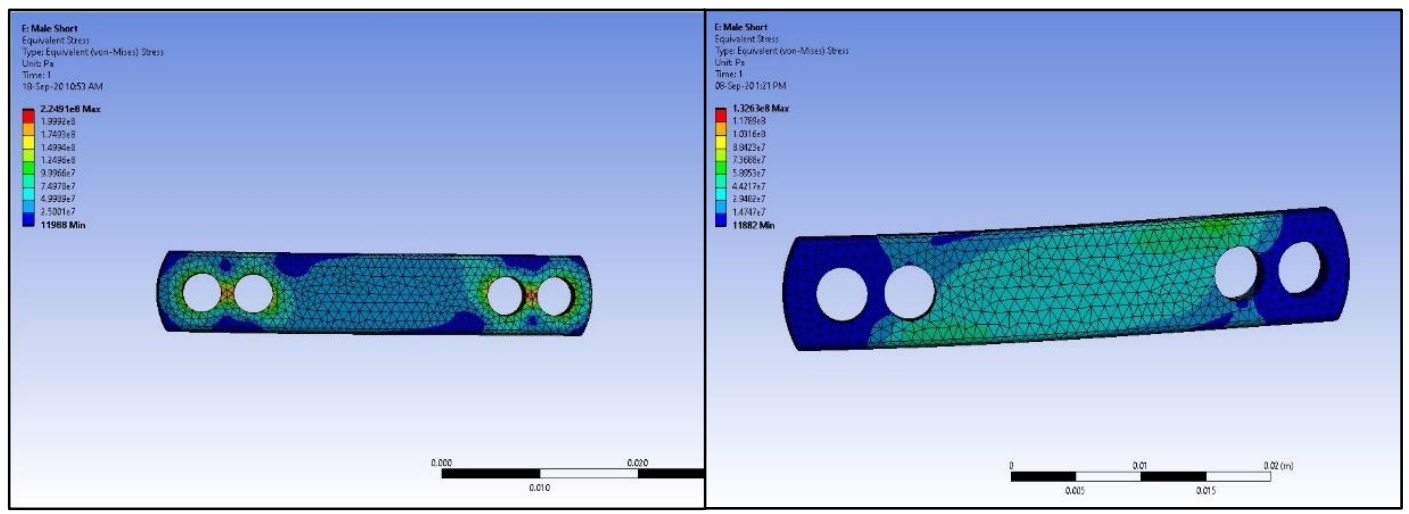

(a)

(b)

Figure 9: a) FEA results for the commercial straight reconstruction plate; b) FEA results for the parametric reconstruction plate 
Severe mandible trauma often requires resection of the affected region. The resulting functional and aesthetic impairment can be mended with various reconstruction methods, including mandible reconstruction plates. The manual bending of reconstruction plates often results in plate fracture, which is a cause of serious concern during implantation. The repeated bending results in weak areas, and residual stresses may lead to fractures when the plate experiences additional stress. The present study proposed a novel reconstruction plate to reduce lead time, to improve fit, and to reduce residual stress and surgical guesswork.

The preliminary comparison tests of the mandible/plate combinations showed that the parametric plate followed the shape of the mandible reasonably well, apart from the area between the angle and the second premolar, where interference occurred. It is difficult to bend the plate during surgery if it is undersized. Thus here are two possible solutions. Either the parametric template could be oversized before additive manufacturing, which would remove the interference error, although intra-operative bending would be required; or adding another landmark on the parametric template in this region could reduce the interference.

The FEA results show that the parametric reconstruction plate experiences lower maximum Von Mises stress and a lower average stress value than a conventional reconstruction plate that has undergone deformation. This is due to significantly less plastic deformation, if any, in the parametric plate. Multiple studies in the literature indicate that conventional plates experience higher maximum and average stress values than custom plates owing to plastic deformation [4] [21].

Traditionally, patient-specific implants require extensive pre-planning, design work, and analysis. The implant developed in this study potentially reduces the lead time, as the template only needs to be adjusted using mandible measurements, and then generated via additive manufacturing. This template and implant could reduce pre-operative planning and intra-operative guesswork while maintaining mandible functionality and aesthetic appearance. A decrease in post-operative complications, such as mandible fracture, plate fracture, and protrusion, is expected.

The FEA literature related to mandible reconstruction is extensive and diverse. The FEA results in this study are limited by the theoretical assumptions made about the loading conditions and material properties. The muscle forces were considered as point loads. By contrast, some literature only consideres a bite force, while other literature models the muscles over a fixed attachment area. Numerous physiological factors affect the material properties of cortical and trabecular bone in the mandible [22]. The mandible material properties were therefore assumed to be homogeneous and isotropic.

It is important to note that the parametric plate is merely a better approximation and not a perfect fit. It is not a complete patient-specific design, and does not account for irregular contours on the mandible. However, the minor adjustments that the parametric plate might require are a significant improvement over the surgical guesswork that is present when working with conventional reconstruction plates.

\section{CONCLUSION}

This study proposed a parametric reconstruction plate design that has the potential to reduce the effort associated with the pre-planning and intra-operative bending involved with conventional mandible reconstruction plates. The parametric plate might also reduce the time and effort normally required for patient-specific implant design. The parametric mandible reconstruction plate provides the following benefits: 1 ) it is structurally superior owing to the lack of large amounts of plastic deformation; 2 ) it offers better mandible approximation, with little adjustment required, which can reduce the chance of mechanical failure; 3 ) it maintains facial contours; and 4) it has a shorter design time than patient-specific implants.

It is clear from the RMS value of $2.4 \mathrm{~mm}$, measured during the comparison test, that the implant is a vast improvement over the commercial straight plate. Current commercial implants are spaced $\pm 1 \mathrm{~mm}$ from the mandible. This reduces the need for the implant to match the underlying geometry, and provides a better fit. However, plastic deformation in commercial plates is relatively high, regardless of the improved fit. Theoretically speaking, a surgeon will only need, on average, to bend the plate $1.4 \mathrm{~mm}$ to fit the mandible. This reduces not only the guesswork associated with the shaping of the implant, but the plastic deformation too. Future work should include a physical comparison test to confirm the implant fit. 
The FEA evaluation addressed the high maximum and average stress values in conventional plates, with noticeably lower stress values in the parametric plate. This indicates that the parametric plate's strength is sufficient for clinical purposes. In the context of mandible reconstruction, the parametric plate provides an improved design over conventional reconstruction plates. FEA is merely a tool, and should not be completely trusted. Therefore it is recommended that future work conduct a physical test, potentially using mandible cadavers, to confirm the FEA. It is highly likely that the physical testing would reach the same conclusion as the simulation.

\section{REFERENCES}

[1] Matsuo, K. \& Palmer, J. 2009. Coordination of mastication, swallowing and breathing. Japanese Dental Science Review, 45(1), pp. 31-40.

[2] Elias, C.N. 2011. Factors affecting the success of dental implants, $1^{\text {st }}$ ed. Intech Publishing.

[3] Seol, G., Jeon, E., Lee, J., Choi, S., Kim, J., Kwon, T. \& Paeng, J. 2014. Reconstruction plates used in the surgery for mandibular continuity defect. Journal of the Korean Association of Oral and Maxillofacial Surgeons, 40(6), pp. 266-271.

[4] Mohammed, M.I., Fitzpatrick, A.P. \& Gibson, I. 2017. Customized design of a patient specific 3D printed whole mandible implant. KnE Engineering, 2(2), p. 104-111.

[5] Yamada, H., Nakaoka, K., Sonoyama, T., Kumagai, K., Ikawa, T., Shigeta, Y., Harada, N., Kawamura, N., Ogawa, T. \& Hamada, Y. 2016. Clinical usefulness of mandibular reconstruction using custom-made titanium mesh tray and autogenous particulate cancellous bone and marrow harvested from tibia and/or ilia. Journal of Craniofacial Surgery, 27(3), pp. 586-592.

[6] Gillingham, R. 2019. Retrospective study on mandible morphology towards improving implant design. M.Eng. thesis. Stellenbosch University.

[7] Cignoni, P., Rocchini, C. \& Scopigno, R. 1998. Metro: Measuring error on simplified surfaces. Computer Graphics Forum, 17(2), pp. 167-174.

[8] Al-Ahmari, A., Nasr, E., Moiduddin, K., Anwar, S., Kindi, M. \& Kamrani, A. 2015. A comparative study on the customized design of mandibular reconstruction plates using finite element method. Advances in Mechanical Engineering, 7(7), pp. 1-11.

[9] Gutwald, R., Alpert, B. \& Schmelzeisen, R. 2003. Principle and stability of locking plates. The Keio Journal of Medicine, 52(1), pp. 21-24.

[10] Wong, R., Tideman, H., Merkx, M., Jansen, J. \& Goh, S. 2012. The modular endoprosthesis for mandibular body replacement. Part 2: Finite element analysis of endoprosthesis reconstruction of the mandible. Journal of CranioMaxillofacial Surgery, 40(8), pp. e487-e497.

[11] Aquilina, P., Chamoli, U., Parr, W., Clausen, P. \& Wroe, S. 2013. Finite element analysis of three patterns of internal fixation of fractures of the mandibular condyle. British Journal of Oral and Maxillofacial Surgery, 51(4), pp. 326-331.

[12] Arbag, H., Korkmaz, H., Ozturk, K. \& Uyar, Y. 2008. Comparative evaluation of different miniplates for internal fixation of mandible fractures using finite element analysis. Journal of Oral and Maxillofacial Surgery, 66(6), pp. $1225-1232$.

[13] Oguz, Y., Uckan, S., Ozden, A., Uckan, E. \& Eser, A. 2009. Stability of locking and conventional 2.0-mm miniplate/screw systems after saggital split ramus osteotomy: Finite element analysis. Oral Surgery, Oral Medicine, Oral Pathology, and Endodontology, 108(2), pp. 174-177.

[14] Narra, N., Valášek, J., Hannula, M., Marcián, P., Sándor, G., Hyttinen, J. \& Wolff, J. 2014. Finite element analysis of customized reconstruction plates for mandibular continuity defect therapy. Journal of Biomechanics, 47(1), pp. 264-268.

[15] Knoll, W., Gaida, A. \& Maurer, P. 2006. Analysis of mechanical stress in reconstruction plates for bridging mandibular angle defects. Journal of Cranio-Maxillofacial Surgery, 34(4), pp. 201-209.

[16] Andersen, K., Pedersen, E. \& Melsen B. 1991. Material parameters and stress profiles within the periodontal ligament. American Journal of Orthodontics and Dentofacial Orthopedics, 99(5), pp. 427-440.

[17] Dittmer, J., Jensen, C., Gottschalk, M. \& Almy, T. 2006. Mesh optimization using a genetic algorithm to control mesh creation parameters. Computer-Aided Design and Applications, 3(6), pp. 731-740.

[18] Wu, C., Lin, Y., Liu, Y. \& Lin, C. 2017. Biomechanical evaluation of a novel hybrid reconstruction plate for mandible segmental defects: A finite element analysis and fatigue testing. Journal of Cranio-Maxillofacial Surgery, 45(10), pp. 1671-1680.

[19] O'Toole, B., Karpanan, K. \& Feghhi, M. 2006. Experimental and finite element analysis of preloaded bolted joints under impact loading. $47^{\text {th }}$ AIAA/ASE/ASCE/AHS/ASC Structures, Structural Dynamics, and Materials Conference, 01 - 04 May, Rhode Island.

[20] Murugan, J., Kurian, T., Jayaprakash, J. \& Sreedharapanickar, S. 2015. 3-D analysis of flanged joints through various preload methods using ANSYS. Journal of the Institution of Engineers (India): Series C, 94(4), pp. 407-417.

[21] Gutwald, R., Jaeger, R. \& Lambers, F. 2016. Customized mandibular reconstruction plates improve mechanical performance in a mandibular reconstruction model. Computer Methods in Biomechanics and Biomedical Engineering, 20(4), pp. 426-435.

[22] Scwartz-Dabney, C. \& Dechow, P. 2003. Variations in cortical material properties throughout the human dentate mandible. American Journal of Physical Anthropology, 120(3), pp. 252-277. 